\title{
Geomorphology of the small island of Tidore and Hiri (North Maluku, Indonesia)
}

\author{
Bachtiar W Mutaqin ${ }^{1 *}$, Muh Aris Marfai ${ }^{1,2}$, Danang Sri Hadmoko ${ }^{1}$, Franck Lavigne ${ }^{3}$, Audrey Faral $^{3}$, Helvetia \\ Wijayanti ${ }^{1}$ and Widiyana Riasasi $^{4}$ \\ ${ }^{1}$ Coastal and Watershed Research Group, Faculty of Geography, Universitas Gadjah Mada, 55281 Bulaksumur, Indonesia \\ ${ }^{2}$ Geospatial Information Agency, 16911 Cibinong, Indonesia \\ ${ }^{3}$ Université Paris 1 Panthéon Sorbonne, Laboratoire de Géographie Physique UMR 8591, 92190 Meudon, France \\ ${ }^{4}$ Geography Department, Universitas Amikom Yogyakarta, 55281 Sleman, Indonesia
}

\begin{abstract}
Tidore and Hiri Islands in North Maluku Province is the result of a complex tectonic setting. In contrast with Ternate Island and its well-known volcano, Gamalama volcano, there is still a lack of research about volcanic information or volcanic landform in Tidore and Hiri Islands. Even though the two islands also have volcanoes, i.e., Hiri and Tidore/Kiematubu volcano. This study aims to provide geomorphological information, especially in Tidore and Hiri Islands, since this information is hard to find whereas it is very important to disaster mitigation and landuse planning. We used remote sensing images, digital elevation models (DEM), and geological maps to classify geomorphological information of the small island of Tidore and Hiri in the North Maluku based on geomorphological aspects, i.e., morphology, morphogenesis, morpho-chronology, and morpho-arrangement. As a volcanic island, the slope in Tidore and Hiri Island is dominated by a slightly steep $\left(8^{\circ}-16^{\circ}\right)$ and a steep slope $\left(16^{0}-35^{\circ}\right)$, while the relief is dominated by hills and mountainous. Volcanic landforms on Tidore and Hiri Islands are characterized by relatively symmetrical cone-shaped volcanic cones, which are accumulations of falling pyroclastic material and lava ejected from magma vents. Volcanic islands include the case of Tidore and Hiri Island have radial centrifugal river flow patterns. The material on Tidore and Hiri Islands is dominated by Holocene volcanic rocks. In Tidore, there is alluvial material on the west and east coasts of the island. This study result also can be developed into more detailed geomorphological maps, or landscape evolution in a volcanic island, or spatial planning.
\end{abstract}

\section{Introduction}

North Maluku in the eastern part of Indonesia is a tectonically active region since it is situated in the convergence of Australian, Eurasian, and Philippine Sea plates [1]. As a result, there are several volcanoes and small islands in the North Maluku province, including Tidore and Hiri Islands. These two islands are located between the main island of Halmahera and the Halmahera arc and stretch along a volcanic arc from Morotai in the northern part to the Bacan Island in the southern part of the North Maluku province (Figure 1).

Compared with other volcanoes in this region, the Gamalama volcano in Ternate Island is categorized as one of the most active volcanoes in the North Maluku Province during the Holocene era [2]. That is why there are numerous researches in Ternate Island related to Gamalama volcano, for example, evacuation route planning during the Gamalama eruption, landslideinduce tsunami due to Gamalama instability, or disaster mitigation in Ternate $[3,4,5]$.

In contrast with Ternate Island and its well-known volcano, Gamalama volcano, there is still a lack of research about volcanic information or volcanic landform in Tidore and Hiri Islands. Even though the two islands also have volcanoes, i.e., Hiri and Tidore/Kiematubu volcano [1,6,7]. Furthermore, Tidore Island also has a caldera form with a $2-\mathrm{km}$ diameter in the northern part of Tidore Island. Tidore Island is made up of two quite distinct volcanic structures. Kiematubu is a stratovolcano with a stunningly conical and circular peak on Tidore Island's southern part $[8,9,10]$.

With a height of $1,730 \mathrm{~m}$, Kiematubu volcano is the highest volcano compared with other volcanoes in the North Maluku province. The vast and lower landform in the northern part of Tidore Island can be identified as a caldera from Holocene era [7,10].

Meanwhile, Hiri Island, which located 9-km in the north of Gamalama volcano, is a small island with $3-\mathrm{km}$ of diameter and dominated by forest. Although it was identified as Holocene stratovolcano, nothing is known about this volcano $[7,10]$. With a height of $630-\mathrm{m}$, Hiri volcano is known as the northernmost volcano along the sequence of small volcanic islands which is located separate from the main island of Halmahera in the North Maluku province (Figure 2). This study aims to provide geomorphological information, especially in Tidore and Hiri Islands, since this information is hard to find whereas it is very important to disaster mitigation and landuse planning [11].

\footnotetext{
* Corresponding author: mutaqin@ugm.ac.id
} 


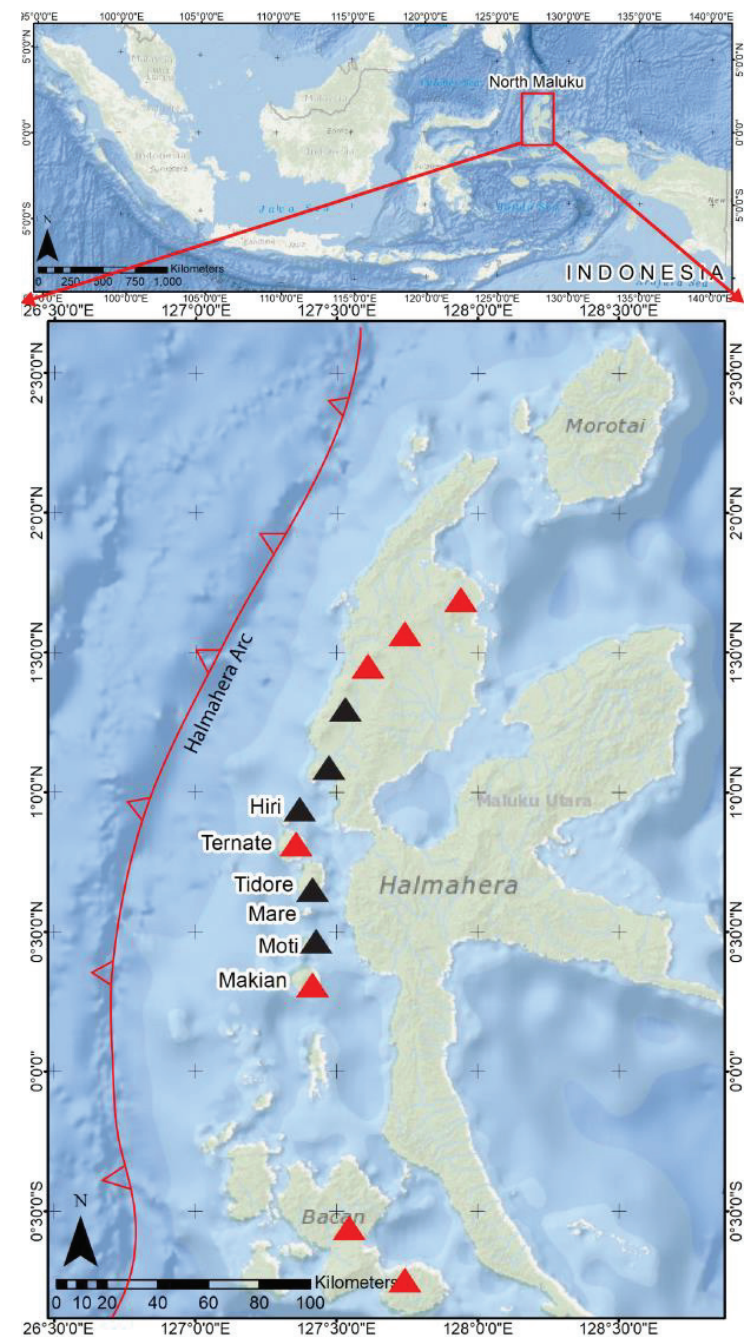

Fig. 1. Tidore and Hiri Islands in the North Maluku.

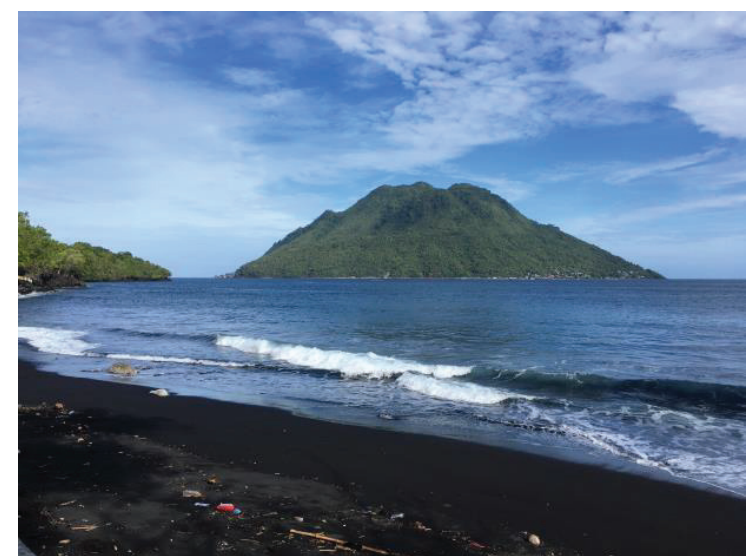

Fig. 2. View of Hiri Island from Sulamadaha Beach in the northern part of Ternate Island.

\section{Material and methods}

Spatial data as the main input in this research include remote sensing images, digital elevation models (DEM) from the Indonesian Geospatial Agency, and secondary data on geological maps from the Indonesian Geological Agency. Terrain features and landforms can be identified through satellite imagery, DEM data, and
GIS-based mapping [12,13]. The advantage of multispectral satellite imagery is that it can be used to identify features in a large area and has been used in various studies related to mapping of terrain features and landforms $[6,11,13,14]$. DEM data is also used in river flow extraction and recognizes flow patterns that indicate a landform [14].

The combination of analysis of satellite imagery, DEM, aerial photography, and geological maps can also be used to identify the geomorphic classification of surface materials and landform types [15]. We classify geomorphological information of the small island of Tidore and Hiri in the North Maluku based on geomorphological aspects, i.e., morphology, morphogenesis, morpho-chronology, and morphoarrangement.

\section{Results and discussion}

Morphological information in this study uses relief and slope analysis. There are two data in determining the relief, namely the slope and elevation. The elevation is directly obtained from the DEM data, while the slope needs to proceed from the DEM data [14]. Relief is classified into 4, namely plain, hillock, hill, and mountainous. As a volcanic island, the slope in Tidore and Hiri Island is dominated by a slightly steep $\left(8^{\circ}-16^{\circ}\right)$ and a steep slope $\left(16^{\circ}-35^{\circ}\right)$ [16]. While the relief is dominated by hills and mountainous (Figure 3 ).

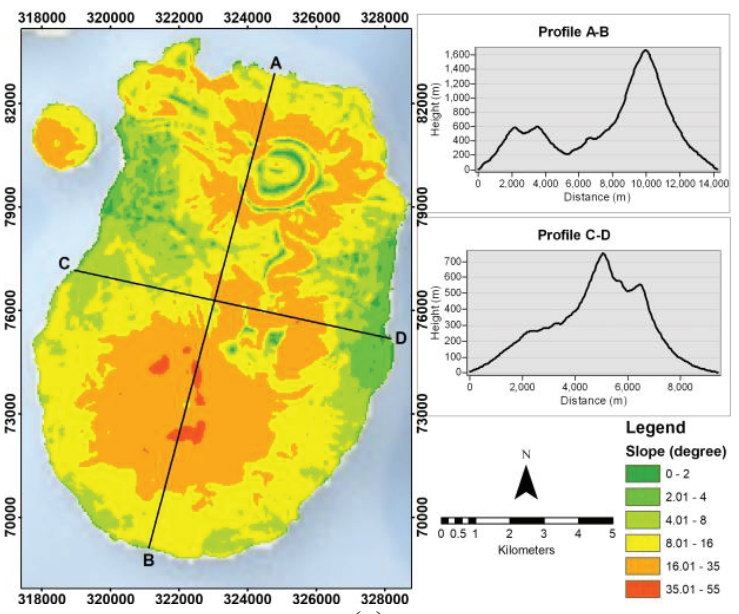

(a)

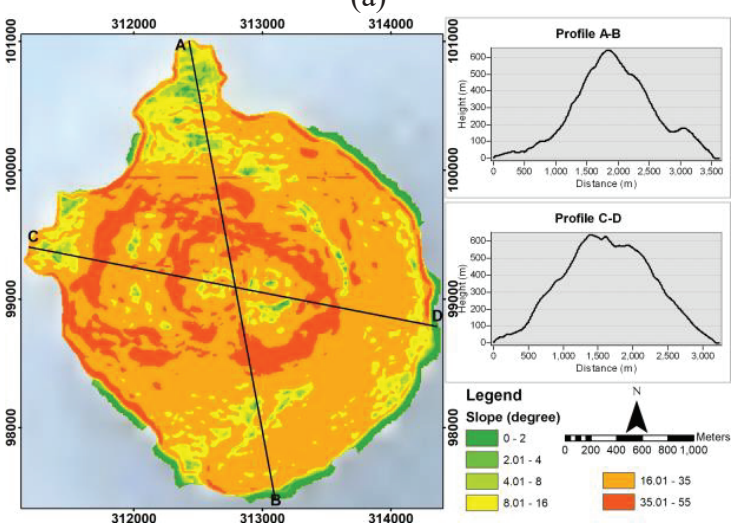

(b)

Fig. 3. Slope and relief in (a) Tidore and (b) Hiri Islands. 
The middle and upstream areas in the form of mountains and hills are used as forests and plantations, while the plains relief is used as agricultural land and settlements. The morphology of the plains has a limited area around the coast, both in Tidore and Hiri Islands. Hence, settlements and public infrastructure are concentrated along the coast (Figure 4).

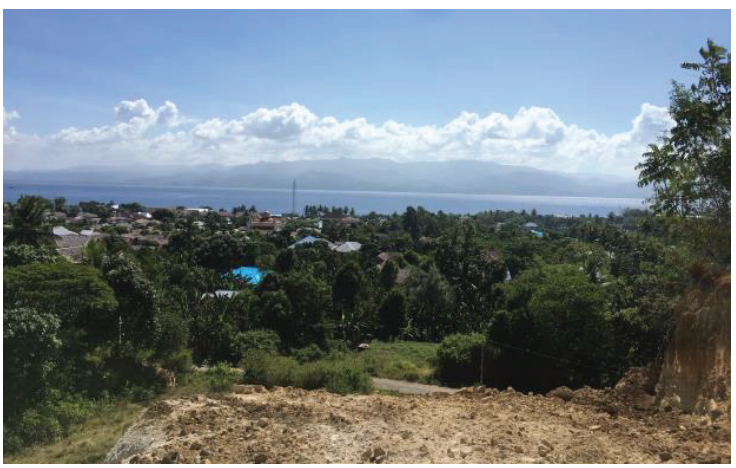

(a)

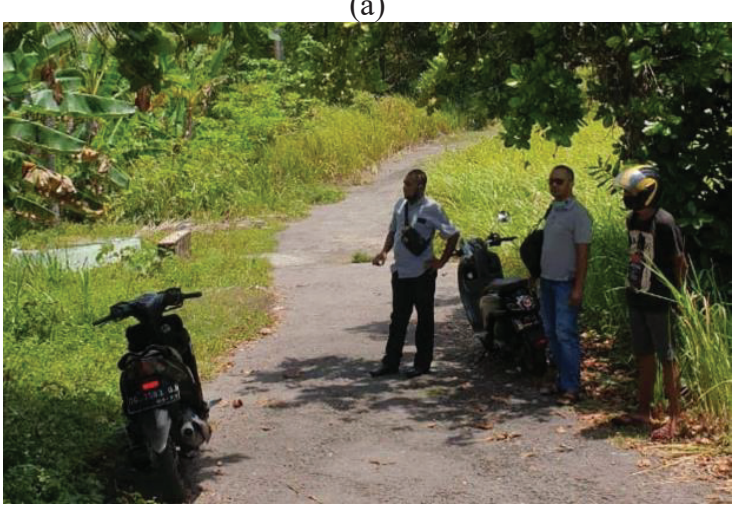

(b)

Fig. 4. (a) Settlements and public infrastructure are concentrated along the coast of Tidore which has plains relief; and (b) Mountains and hills are used as forests and plantations in Hiri Island.

Volcanic landforms on Tidore and Hiri Islands are characterized by relatively symmetrical cone-shaped volcanic cones, which are accumulations of falling pyroclastic material and lava ejected from magma vents $[12,13]$. The caldera on the north side of Tidore Island has a diameter of $2 \mathrm{~km}$ and was formed by the explosive eruption of the main magma vent. In addition to a very large eruption, a caldera can also be formed due to the collapse of the walls and bottom of a volcanic crater. Occasionally, craters or calderas have been filled with lava flows, lava domes, or water, and often have been eroded in older volcanic cones.

Flow pattern information requires river flow data on the identified island. The flow can be obtained by extracting DEM data into flow accumulation (Figure 5). In the flow accumulation data, pixels with high flow accumulation values are locations of concentrated flows and can be used to identify river flows, both permanent (perennial) and periodic (intermittent) rivers. If the river flow on the island can be detected, the flow pattern can also be interpreted. The results of this river flow detection are checked for correctness through field activities.

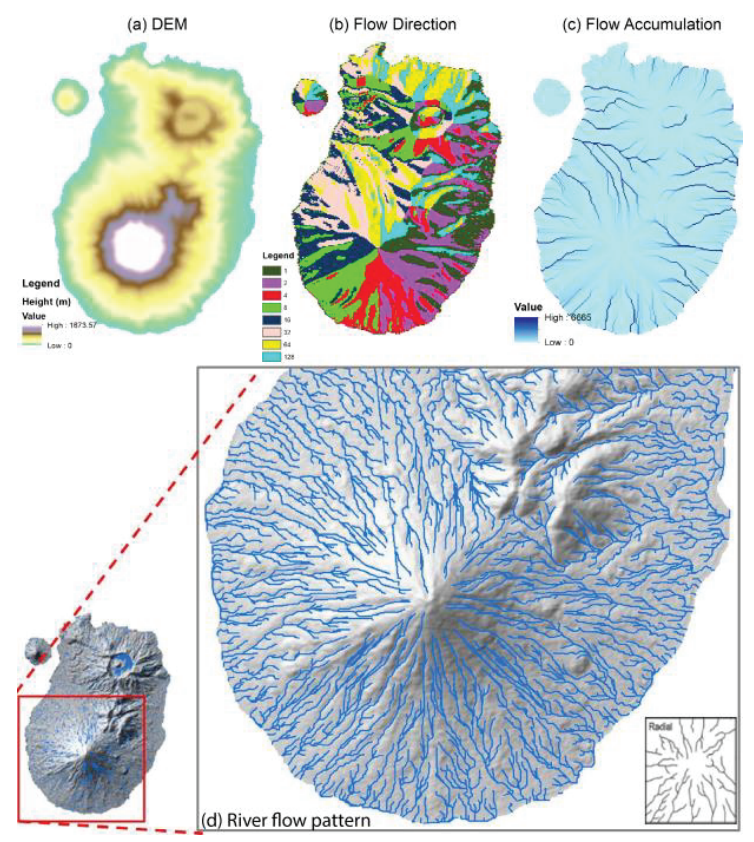

Fig. 5. An example of the extraction process of flow accumulation from DEM data for interpretation of characteristics of river flow patterns in Tidore Island: (a) DEM, (b) Flow direction, (c) Flow accumulation, and (d) River flow pattern.

At the locations of the field survey, river flows were found in accordance with the detection made through remote sensing data. Thus, the results of flow extraction through remote sensing data produce data that is in accordance with the conditions in the field and can be used as a method of extracting flow patterns (Figure 6).

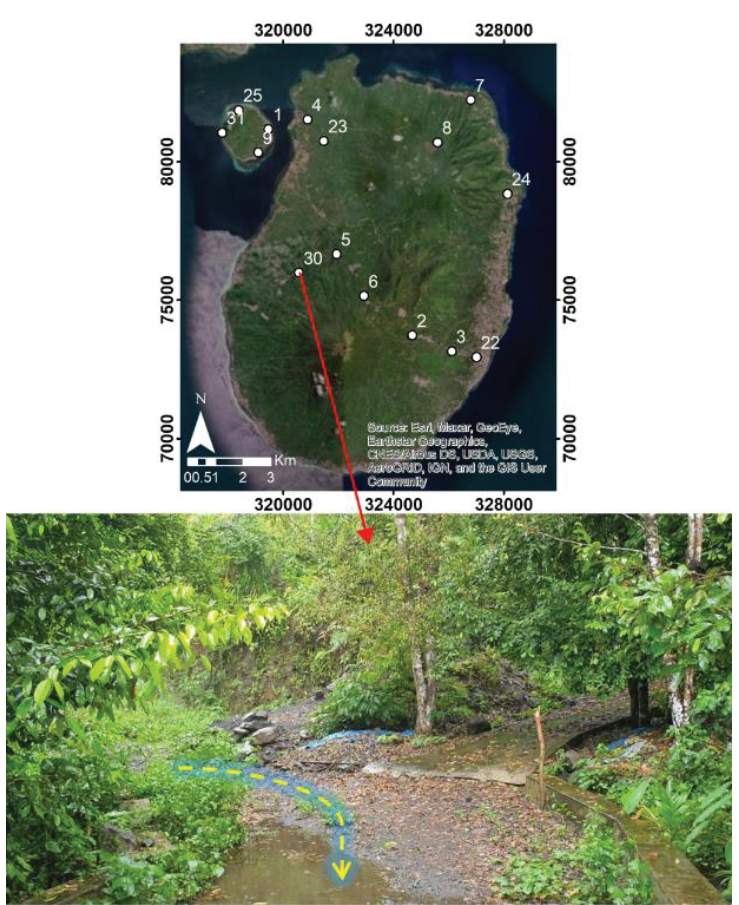

Fig. 6. An example of field survey in point number 30 for river flow pattern in Tidore Island.

Volcanic islands have a characteristic river flow pattern in the form of radial centrifugal, while non- 
volcanic islands have different river flow patterns, such as dendritic [17]. This also includes the case of Tidore and Hiri Island where both islands have radial centrifugal river flow patterns.

Material identification in Tidore and Hiri Island is carried out through geological map analysis and validation during field surveys. Tidore and Hiri islands were formed by volcanism processes, which are characterized by their relatively spherical shape with lava, pyroclastic, or sub-aerial depositional rock material $[7,12,18,19]$. The material on Tidore and Hiri Islands is dominated by Holocene volcanic rocks. In Tidore, there is alluvial material on the west and east coasts of the island $[6,7]$.

\section{Conclusions}

Here we present the geomorphological information of Tidore and Hiri Island in the eastern part of Indonesia. This study result is important as a basis data for disaster mitigation and planning, considering the difference of terrain and landform features in these islands. Tidore and Hiri Island were classified as volcanic islands due to their morphology, morphogenesis, morphochronology, and morpho-arrangement.

As a volcanic island, the slope in Tidore and Hiri Island is dominated by a slightly steep $\left(8^{\circ}-16^{\circ}\right)$ and a steep slope $\left(16^{0}-35^{\circ}\right)$, while the relief is dominated by hills and mountainous. Volcanic landforms on Tidore and Hiri Islands are characterized by relatively symmetrical cone-shaped volcanic cones, which are accumulations of falling pyroclastic material and lava ejected from magma vents. Volcanic islands include the case of Tidore and Hiri Island have radial centrifugal river flow patterns. The material on Tidore and Hiri Islands is dominated by Holocene volcanic rocks. In Tidore, there is alluvial material on the west and east coasts of the island. This study result also can be developed into more detailed geomorphological maps, or landscape evolution in a volcanic island, or spatial planning.

This research was funded by the grant of National Basic Research from the Indonesian Ministry of Research, Technology and Higher Education - GASTROPODE Project. We thank anonymous reviewers for their constructive comments on the manuscript. The authors also acknowledge the Regional Disaster Management Agency of North Maluku.

\section{References}

1. E. Gunawan, F. Ghozalba, Syauqi, Y. Widiastomo, I. Meilano, N.R. Hanifa, Daryono, S. Hidayati, Geotech. Geol. Eng. 35, 425 (2017)

2. A. Hidayat, M.A. Marfai, D.S. Hadmoko, GeoJournal, In Press, (2020)

3. S.F. Syiko, A.R. Turniningtyas, A. Yudono. Procedia Environ. Sci. 17, 344 (2013)

4. Saaduddin, J. Neuberg, M.E. Thomas, J. Hill. The Mt Gamalama Instability Level in Generating Landslide-Induced Tsunami in Ternate Island, Indonesia, in Understanding and Reducing
Landslide Disaster Risk, WLF 2020, Springer (2021)

5. A. Hidayat, M.A. Marfai, D.S. Hadmoko. Int. J. GEOMATE. 18, 66 (2020)

6. B.W. Mutaqin, W. Handayani, F.S.C. Rosaji, D. Wahyuningtyas, M.A. Marfai. Jurnal Geografi. 13, 2 (2021)

7. T. Apandi, D. Sudana. Geologic map of Ternate quadrangle, North Maluku, scale 1:250.000 (Geological Research and Development Center, Bandung, 1980)

8. K. Cosburn, M. Roy. J Volcanol Geotherm Res. 407, 107123 (2020)

9. D. Karátson, M. Favalli, S. Tarquini, A. Fornaciai, G. Wörner. J Volcanol Geotherm Res. 193, 3-4 (2010)

10. Global Volcanism Program. Volcanoes of the World, v. 4.10.0 (14 May 2021) (Smithsonian Institution, 2021)

11. A.Quesada-Román, P.M. Pérez-Briceño. J. Maps. 15, 2 (2019)

12. M. Kervyn, F. Kervyn, R. Goossens, S.K. Rowland, G.G.J. Ernst. Geol. Soc. Spec. Publ. 283, 5 (2007)

13. J. Napieralski, I. Barr, U. Kamp, M. Kervyn. Remote sensing and GIScience in geomorphological mapping, in Treatise on Geomorphology, Elsevier (2013)

14. B.W. Mutaqin, F. Lavigne, Y. Sudrajat, L. Handayani, P. Lahitte, C. Virmoux, Hiden, D.S. Hadmoko, J.C. Komorowski, N.D. Hananto, P. Wassmer, Hartono, K. Boillot-Airaksinen, Geomorphology 327, 338-350 (2019)

15. J.-C. Thouret. Earth-Sci. Rev. 47, 1-2 (1999)

16. B.W. Mutaqin, M.A. Marfai, D.S. Hadmoko, H. Wijayanti, F. Lavigne, A. Faral, J. Hunan Univ. Nat. Sci. 48, 6 (2021)

17. J.C. Santamarta, R.J. Lario-Bascones, J. RodríguezMartín, L.E. Hernández-Gutiérrez, R. Poncela. IERI Procedia. 9, 135 (2014)

18. H.P. Chan, C.P. Chang, T.H. Lin, M. Blackett, H. Kuo-Chen, A.T.S. Lin. Int. J. Remote Sens. 41, 4 (2020)

19. J.J. Coello-Bravo, A. Márquez, R. Herrera, M.J. Huertas, E. Ancochea. J Volcanol Geotherm Res. 401, 106980 (2020) 